\title{
Oligomannurarate sulfate inhibits CXCL12/SDF-1- mediated proliferation and invasion of human tumor cells in vitro
}

\author{
Wei-wei WEN, Shao XIE, Xian-liang XIN, Mei-yu GENG, Jian DING*, Yi CHEN* \\ Division of Anti-Tumor Pharmacology, State Key Laboratory of Drug Research, Shanghai Institute of Materia Medica, Chinese Academy \\ of Science, Shanghai 201203, China
}

\begin{abstract}
Aim: JG6 is a novel marine-derived oligosaccharide that has shown to inhibit angiogenesis and tumor metastasis. In this study, we sought to identify the potential target responsible for the anti-cancer activity of JG6.

Methods: Human liver cancer cell line Bel-7402 and human cervical cancer cell line HeLa were examined. CXCL12-stimulated cell proliferation and migration were determined using a CCK-8 kit and a transwell assay, respectively. Western blotting was performed to examine the changes in CXCL12/CXCR4 axis. Molecular docking and surface plasmon resonance (SPR) were performed to characterize the possible interaction between JG6 and the CXCL12/CXCR4 axis.

Results: Treatment with CXCL12 potently stimulated the proliferation and migration in both Bel-7402 and HeLa cells. Co-treatment of the cells with JG6 $(10,50$ and $100 \mu \mathrm{g} / \mathrm{mL})$ dose-dependently impeded the CXCL12-stimulated cell proliferation and migration.

Furthermore, CXCL12 rapidly induced phosphorylation of AKT, ERK, FAK and Paxillin in Bel-7402 and HeLa cells, whereas pretreatment with JG6 dose-dependently inhibited the CXCL12-induced phosphorylation of these proteins. The SPR assay showed that JG6 bound to CXCL12 with a high affinity. In molecular docking study, JG6 appeared to interact with CXCL12 via multiple polar interactions, including 6 ionic bonds and 7 hydrogen bonds.
\end{abstract}

Conclusion: Inhibition of the CXCL12/CXCR4 axis by JG6 may account for its anticancer activity.

Keywords: cancer; anticancer drug; oligosaccharide; oligomannurarate sulfate; JG6; CXCL12/CXCR4 axis; surface plasmon resonance; molecular docking

Acta Pharmacologica Sinica (2013) 34: 1554-1559; doi: 10.1038/aps.2013.83; published online 21 Oct 2013

\section{Introduction}

CXCL12, also called stromal cell-derived factor-1 (SDF-1), is a CXC chemokine that binds primarily to CXC receptor 4 (CXCR4). This binding induces intracellular signaling that plays a pivotal role in chemotaxis, cell survival, proliferation, and metastasis of CXCR4+ tumor cells to organs that express CXCL12 ${ }^{[1,2]}$. It has been reported that CXCR4+ cancers metastasize to bones and lymph nodes in a CXCL12-dependent manner ${ }^{[3,4]}$. Therefore, the CXCL12/CXCR4 axis has emerged as a potential target for cancer therapy.

Increasing effort has been made in impeding the function of the CXCL12/CXCR4 axis by targeting either the ligand or the receptor using small-molecule receptor antagonists, receptorbinding antibodies, or modified chemokines ${ }^{[5,6]}$. Among these

\footnotetext{
* To whom correspondence should be addressed.

E-mail ychen@simm.ac.cn (Yi CHEN); suozhang@mail.shcnc.ac.cn (Jian DING)

Received 2013-04-20 Accepted 2013-05-13
}

options, blocking the access of CXCL12 to CXCR4 is an effective approach. It has been reported that glycosaminoglycans (GAGs) and syndecan-4 hindered the invasion of human tumor cells (HeLa cells) via blocking the interaction between CXCL12 and CXCR4 ${ }^{[7]}$, and this finding was supported by the structural analysis of CXCL12's interactions with GAGs ${ }^{[8,9]}$. Accordingly, heparin, a sulfated glycosaminoglycan, blocked CXCL12-induced human cancer cell growth, migration, and invasion $^{[7,10]}$. Furthermore, treatment of human hepatoma cells with a series of GAG mimetics inhibited CXCL12-induced migration and invasion ${ }^{[11]}$.

JG6 is a novel marine-derived oligosaccharide discovered in our laboratory. JG6 significantly suppressed cancer growth and metastasis in vitro and in vivo ${ }^{[12,13]}$, but the mechanisms remain unclear. Importantly, we have noted that the structure of JG6 resembles the structure of GAGs. Here, we explored whether JG6 has potential anti-cancer activity through its intervention in the CXCL12/CXCR4 axis. 


\section{Materials and methods}

\section{Reagents}

JG6 was created by semi-synthesis followed by sulfate modification by reacting oligomannurarate from sodium alginate with $\mathrm{ClSO}_{3} \mathrm{H}$ in formamide. The $\mathrm{pH}$ of the products was adjusted to 7.0 with $4 \mathrm{~mol} / \mathrm{L} \mathrm{NaOH}$ and desalted using Sephadex G-10. The products were pooled and freeze-dried. Analysis was performed using High Performance Gel Permeation Chromatography (HPGPC) with a G3000W×1 column (300 $\mathrm{mm} \times 7.8 \mathrm{~mm}$ ) (TOSOH, Japan). The structure is depicted in Figure 1. JG6 is composed of $\beta-(1-4)$ glycosidic linked D-mannurarate with sulfate modification of the hydroxyl group at the C2/C3 position. CXCL12 was purchased from R\&D Systems (Minneapolis, MN, USA).

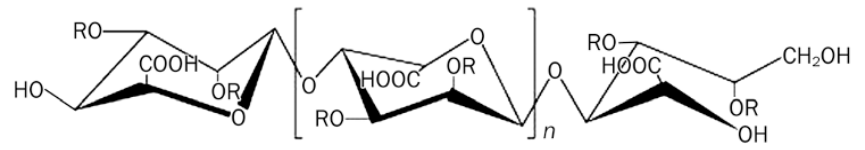

$\mathrm{R}$ on $\mathrm{C} 2$ position $=\mathrm{SO}_{3} \mathrm{Na}$, $\mathrm{R}$ on $\mathrm{C} 3$ position $=\mathrm{H}$ or $\mathrm{SO}_{3} \mathrm{Na}, n=0$ or $1-19$

Figure 1. Chemical structure of JG6.

\section{Cell culture}

Bel-7402 human liver cancer cells and HeLa human cervical cancer cells were obtained from the Institute of Biochemistry and Cell Biology and the American Type Culture Collection, respectively. The cells were grown in RPMI-1640 or highglucose DMEM medium (Gibco, Grand Island, NY, USA) supplemented with $10 \%$ fetal bovine serum (Gibco, Grand Island, NY, USA) and antibiotics (100 U/mL penicillin and 100 $\mu \mathrm{g} / \mathrm{mL}$ streptomycin). The cells were maintained in a $5 \% \mathrm{CO}_{2}$ humidified atmosphere at $37^{\circ} \mathrm{C}$.

\section{Proliferation assay}

Bel-7402 and HeLa cells were incubated in serum-free medium for $6 \mathrm{~h}$ and then exposed to various concentrations of JG6 (0, 10, 50, or $100 \mu \mathrm{g} / \mathrm{mL}$ ) and CXCL12 (300 ng/mL) for $72 \mathrm{~h}$. Cell proliferation was determined using a CCK-8 kit (Dojindo, Kumamoto, Japan).

\section{Migration assay}

The cell migration assay was performed in a transwell Boyden Chamber ( $8 \mu \mathrm{m}$ pore size, Costar, MA, USA). Briefly, tumor cells $\left(3.5 \times 10^{5}\right.$ cells per well) were seeded in the top chamber of the transwell, whereas the lower chamber was filled with culture medium supplemented with 50 or $300 \mathrm{ng} / \mathrm{mL}$ CXCL12 plus JG6 $(0,10,50$, or $100 \mu \mathrm{g} / \mathrm{mL})$. CXCL12 was not added to the negative control group. Cells were cultured for $24-36 \mathrm{~h}$ at $37^{\circ} \mathrm{C}$ in a well-humidified incubator, and then the total migrated cells were fixed, stained with $0.1 \%$ crystal violet, and imaged under a microscope. Stained cells were extracted with $10 \%$ acetic acid and the $O D$ value was measured at $595 \mathrm{~nm}$.

\section{Western blotting analysis}

Cells were starved for $24 \mathrm{~h}$, pre-incubated with JG6 (0, 10, 50, or $100 \mu \mathrm{g} / \mathrm{mL}$ ) for $6 \mathrm{~h}$, and then induced with CXCL12 (R\&D, Minneapolis, MN, USA) at $50 \mathrm{ng} / \mathrm{mL}$ for $15 \mathrm{~min}$. After incubation, cells were lysed in $1 \times$ SDS lysis buffer $(50 \mathrm{mmol} / \mathrm{L}$ Tris- $\mathrm{HCl} \mathrm{pH}$ 6.8, $100 \mathrm{mmol} / \mathrm{L}$ DTT, 2\% SDS, 0.1\% bromophenol blue, and $10 \%$ glycerol), and then the lysates were clarified by centrifugation at $14000 \times g$ for $10 \mathrm{~min}$. Equal amounts of protein were subjected to SDS-PAGE and transferred to nitrocellulose membranes (Amersham Pharmacia Biotech, USA). The membranes were blocked with $5 \%$ nonfat milk and incubated with the corresponding primary antibodies at $4{ }^{\circ} \mathrm{C}$ overnight. The immunoreactive bands were visualized by the SuperSignal West PicoChemiluminescent kit (Pierce Biotechnology, Rockford, IL, USA) using Image Quant LAS4000 (GE, USA). Primary antibodies used include antibodies specific for Phospho-Paxillin (Y118), Paxillin, Fak, phospho-Erk1/2, Erk1/2, phospho-Akt (Ser473) and Akt (Cell Signaling Technology, USA), p-Fak (pY861) (Invitrogen, USA), CXCL12 and CXCR4 (Abcam, UK).

\section{Molecular docking}

The NMR structure of chemokine CXCL12 was retrieved from the Brookhaven Protein Data Bank (PDB entry: 2K03). Chain A and chain C from 2K03 were retained as the receptor, whereas chain B was selected to define the grid box center. Molecular docking was performed using Glide with the XP mode $\mathrm{e}^{[14,15]}$. The compounds were sketched by Maestro and then processed by LigPrep with Epik to treat the protonation states. The docked conformations in the ligand-binding site were selected for further analysis.

\section{Surface plasmon resonance analysis}

The kinetics and specificity of the binding reaction between JG6 and CXCL12 were analyzed using the BIAcore surface plasmon resonance apparatus. Briefly, JG6 was immobilized on an NLC sensor chip according to the Ligand Thiol protocol described in BIA application handbook. To assess real-time binding capacity, 5-80 nmol/L of CXCL12 was injected over the sensor chip surface with the immobilized JG6 and then washed with HBS-EP buffer for $5 \mathrm{~min}$. The sensor chip surface was regenerated using $60 \mu \mathrm{L}$ of $\mathrm{NaCl}(2 \mathrm{~mol} / \mathrm{L})$. All binding experiments were performed at $25^{\circ} \mathrm{C}$ with a constant flow rate of $10 \mu \mathrm{L} / \mathrm{min}$ of HBS-EP. For binding affinity assessment, the association phase was allowed to proceed to equilibrium.

The untreated surface moieties were blocked with ethanolamine. To correct for nonspecific binding and bulk refractive index changes, a blank channel (FC2) without oligosaccharide was employed as a control for each experiment. Sensorgrams for all binding interactions were recorded in real time, and the blank channel readings were subtracted from the results before analysis. Changes in mass due to the binding response were recorded as resonance units ( $\mathrm{Ru})$. Binding kinetics and affinities were determined by SPR using BIAcore software 3.1. 


\section{Statistical analysis}

The data are presented as the mean \pm SD. Statistical significance was analyzed by two-tailed Student's $t$-test. A value of $P<0.05$ was considered significant.

\section{Results}

\section{JG6 impeded CXCL12-induced cancer cell proliferation}

The CXCL12/CXCR4 biological axis plays an important role in regulating tumor cell proliferation. First, we investigated whether JG6 had an impact on CXCL12-stimulated cell growth. The CCK- 8 assay was applied to measure the cell proliferation rates of Bel-7402 cells and HeLa cells. CXCL12 stimulated tumor cell growth, as previously reported ${ }^{[10]}$. The proliferation rate was increased by almost $50 \%$ upon treatment with $300 \mathrm{ng} / \mathrm{mL}$ CXCL12 (Figure 2A). This effect was largely reversed when cells were simultaneously treated with JG6. JG6 caused a dose-dependent suppression of CXCL12stimulated Bel-7402 cell proliferation. The cell proliferation rate was inhibited by $22.2 \%$ at $10 \mu \mathrm{g} / \mathrm{mL}, 46.5 \%$ at $50 \mu \mathrm{g} / \mathrm{mL}$, and $51.0 \%$ at $100 \mu \mathrm{g} / \mathrm{mL}$. Similar results were observed in HeLa cells, for which treatment with 10, 50, or $100 \mu \mathrm{g} / \mathrm{mL}$ JG6 yielded $22.2 \%, 37.2 \%$, and $41.5 \%$ lower cell proliferation rates, respectively, than in the absence of JG6 (Figure 2A). However, JG6 did not inhibit Bel-7402 and HeLa cell proliferation in vitro in normal cell culture conditions (data not shown).

\section{JG6 suppressed CXCL12-induced cancer cell migration}

The CXCL12/CXCR4 biological axis is also known to modulate the chemotactic motility of cancer cells. We next evaluated whether JG6 had an inhibitory effect on this process. As shown in Figure 2B, Bel-7402 cells were responsive to CXCL12 induction at a JG6 concentration of $50 \mathrm{ng} / \mathrm{mL}$ for $48 \mathrm{~h}$ when a notable increase in migrating cells was observed compared to the negative control group (which was incubated without CXC12 and FBS). JG6 inhibited CXCL12-induced migration of Bel-7402 cells in a dose-dependent manner, yielding 100\% inhibition at $100 \mu \mathrm{g} / \mathrm{mL}$. Likewise, although HeLa cells were less responsive to CXCL12-stimulation than Bel-7402 cells, JG6 similarly reduced CXCL12-induced migration in HeLa cells by $44 \%, 88 \%$, and $97 \%$ after treatment with 10,50 , or $100 \mu \mathrm{g} / \mathrm{mL}$ of JG6 (Figure 2C). However, JG6 did not impede Bel-7402 cell migration induced by $10 \%$ FBS (data not shown).

\section{JG6 blocked CXCL12-induced signal transduction}

We showed that JG6 effectively inhibited CXCL12-induced cell proliferation and migration in Bel-7402 and HeLa cells. We then proceeded to explore its effect on downstream signals of the CXCL12/CXCR4 axis. The Western blotting data presented in Figure 3 show that $50 \mathrm{ng} / \mathrm{mL}$ CXCL12 rapidly induced phosphorylation of AKT, ERK, FAK and Paxillin in Bel-7402 and HeLa cells, within 15 min. In contrast, pre-incubation with JG6 for $6 \mathrm{~h}$ inhibited CXCL12-induced phosphorylation of these proteins in a dose-dependent manner. Similar results were observed in HeLa cells.

\section{JG6 interacted with CXCL12}

We next assessed how JG6 affects CXCL12/CXCR4 axis signaling. Previous studies in our laboratory have suggested that the structure of JG6 resembles the structure of GAGs and that GAGs appear to interact with CXCL12. We therefore utilized the SPR assay to identify the possible interaction between CXCL12 and JG6. JG6 was immobilized on NLC sensor chips. When CXCL12 was injected into the biosensor, a typical increase in SPR response corresponding to the association phase was observed in a dose-dependent manner (5-80 nmol/L). Upon displacement of the chemokine by the running buffer, a remarkable decrease in the SPR response signal emerged, consistent with the dissociation phase (Figure $4)$. The binding curve was fitted and demonstrated a multivalent binding mode with a clear association rate constant $\left(k_{\mathrm{on}}\right)$ of $11.7 \mathrm{nmol} / \mathrm{L}$ and an equilibrium dissociation rate constant of $16.5 \mathrm{nmol} / \mathrm{L}$. These data supported the findings above that indicate JG6 has a high affinity for CXCL12.

The automated docking simulation exemplified by JG6CXCL12 interaction was performed to understand the interaction mode between them. The crystal structure of human CXCL12 was utilized as the target structure, whereas the disaccharide of JG6 was used as a docking probe. We found that JG6 docked well to CXCL12 with a low docking energy at $-13.08 \mathrm{kcal} / \mathrm{mol}$. JG6 appeared to interact with CXCL12 via multiple polar interactions, including 6 ionic bonds and 7 hydrogen bonds (Figure 5).

These data, taken together, suggested that JG6 impaired the CXCL12/CXCR4 axis likely via a direct interaction with the chemokine CXCL12, which resulted in impaired intracellular signal transduction downstream of CXCL12 stimulation.

\section{Discussion}

The CXCL12/CXCR4 axis plays a critical role in cancer progression, including cell proliferation, survival, angiogenesis and particularly chemotactic metastasis. As a result, the CXCL12/CXCR4 axis has become a widely studied anti-cancer drug target. In this study, we have shown that JG6, a novel marine-derived oligosaccharide, interferes with the CXCL12/ CXCR4 signaling axis and its associated biological functions in cancer cells. JG6 not only significantly reversed CXCL12induced proliferation of cancer cells but also dramatically diminished CXCL12-mediated cell migration in vitro.

CXCL12 binds to GAGs, such as heparin sulfate (HS). CXCL12 binds to the S-domains of HS with high affinity predominantly through 2-O- and N-sulfate groups ${ }^{[16]}$. HS chains are linear repeating polymers composed of $\beta$ - $D$-glucuronate and $a-D-N$-acetylglucosamine ${ }^{[17]}$ with a relatively uniform pattern of alternating sulfated and unmodified regions along the HS chain ${ }^{[18]}$. Previous studies of HS structure have identified a CXCL12-binding domain ${ }^{[8,19]}$. Moreover, a series of sulfated GAG mimetics targeting CXCL12 exhibited anticancer activity $^{[11]}$. Based on the structural similarity between JG6 and GAGs, we hypothesized that JG6 was likely to bind to CXCL12. Using the SPR assay, we showed that JG6, like 
A

a

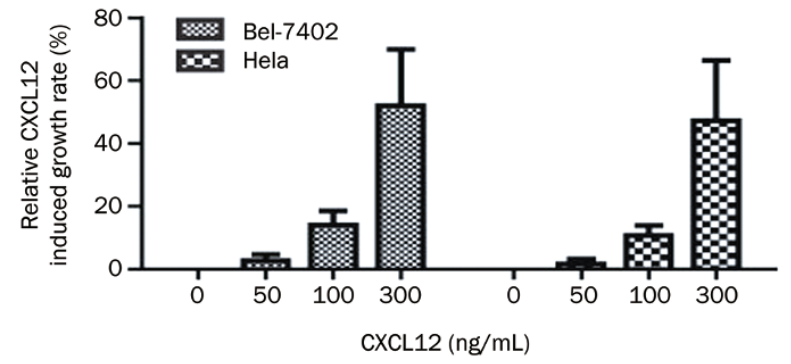

b

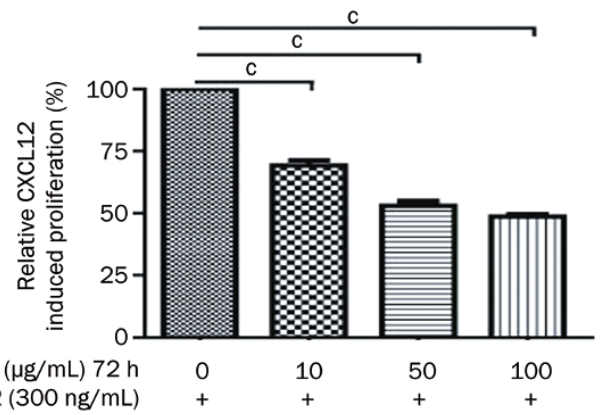

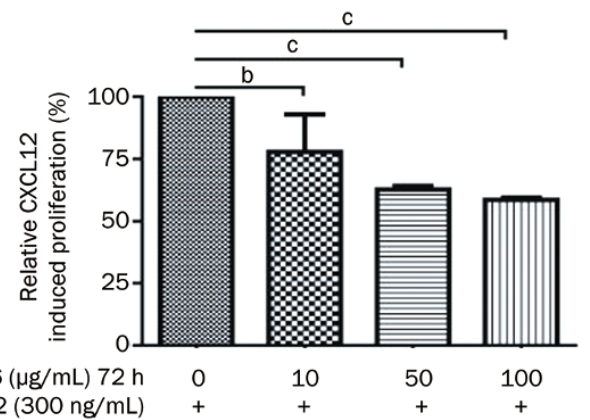

B a

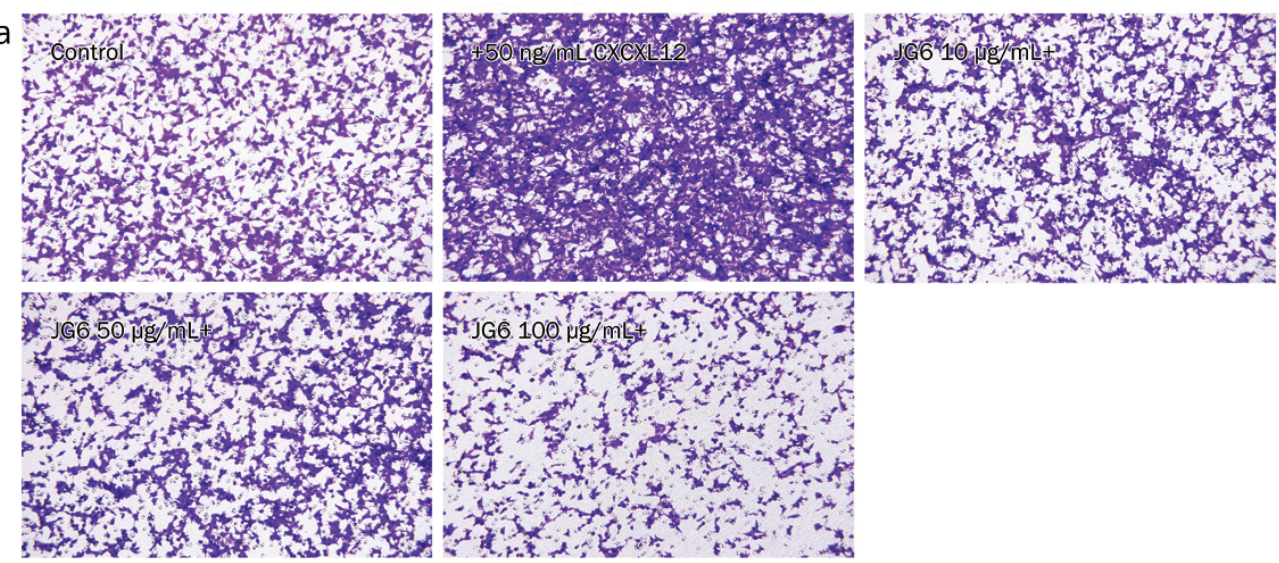

C a
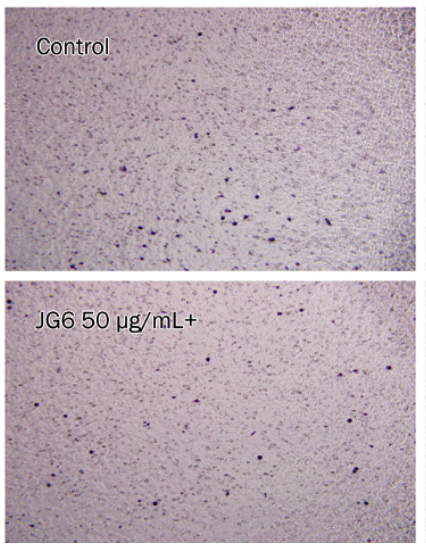
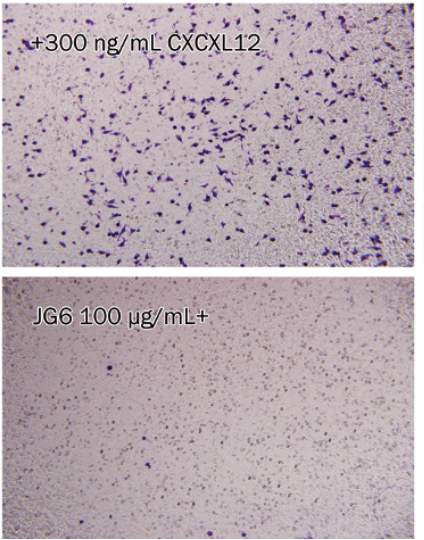

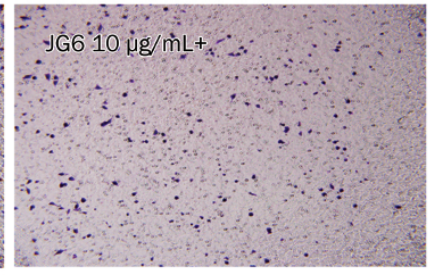

b

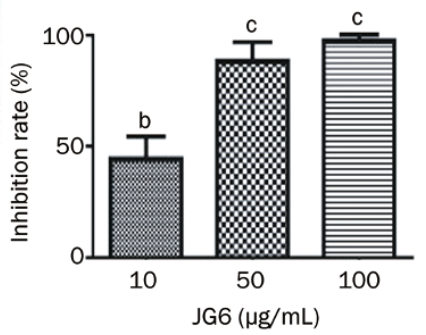

Figure 2. JG6 blocked CXCL12-induced cancer cell proliferation and migration in vitro. (A) JG6 inhibited cancer cell proliferation induced by CXCL12. (a) CXCL12 induced Bel-7402 (left) and HeLa (right) cell proliferation. Bel-7402 (b) and HeLa (c) cells were treated with CXCL12 (300 ng/mL) and 0, 10, 50, or $100 \mu \mathrm{g} / \mathrm{mL}$ JG6 for $72 \mathrm{~h}$. (B, C) JG6 suppressed the cell migration induced by CXCL12 in Bel-7402 (B) and HeLa cells (C). Representative image of cell migration were displayed (magnificaction: 200x; +: treatment with CXCL12). The rate of cell migration inhibition by JG6 were shown as percentage of CXCL12 treatment (mean \pm SD, from three independent experiments. ${ }^{b} P<0.05,{ }^{c} P<0.01$ vs control). 
A

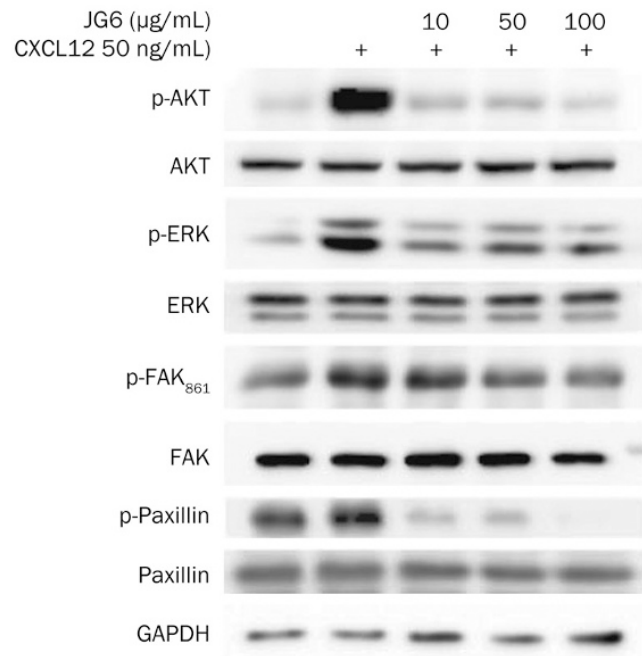

B

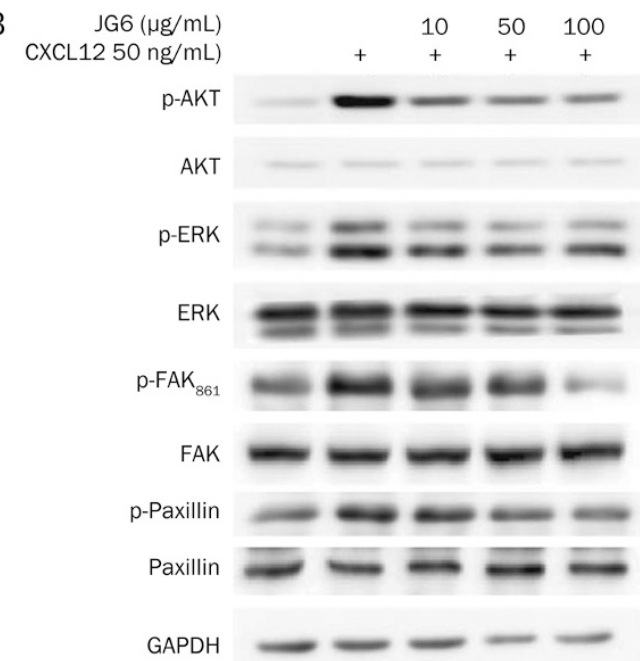

Figure 3. JG6 blocked CXCL12/CXCR4 axis signal transduction in Bel-7402 (A) and HeLa cells (B). These two cell types were starved and then incubated with CXCL12 $(50 \mathrm{ng} / \mathrm{mL})$ alone or CXCL12 pre-incubated with JG6 (10, 50, or $100 \mu \mathrm{g} / \mathrm{mL})$ for $15 \mathrm{~min}$.

A
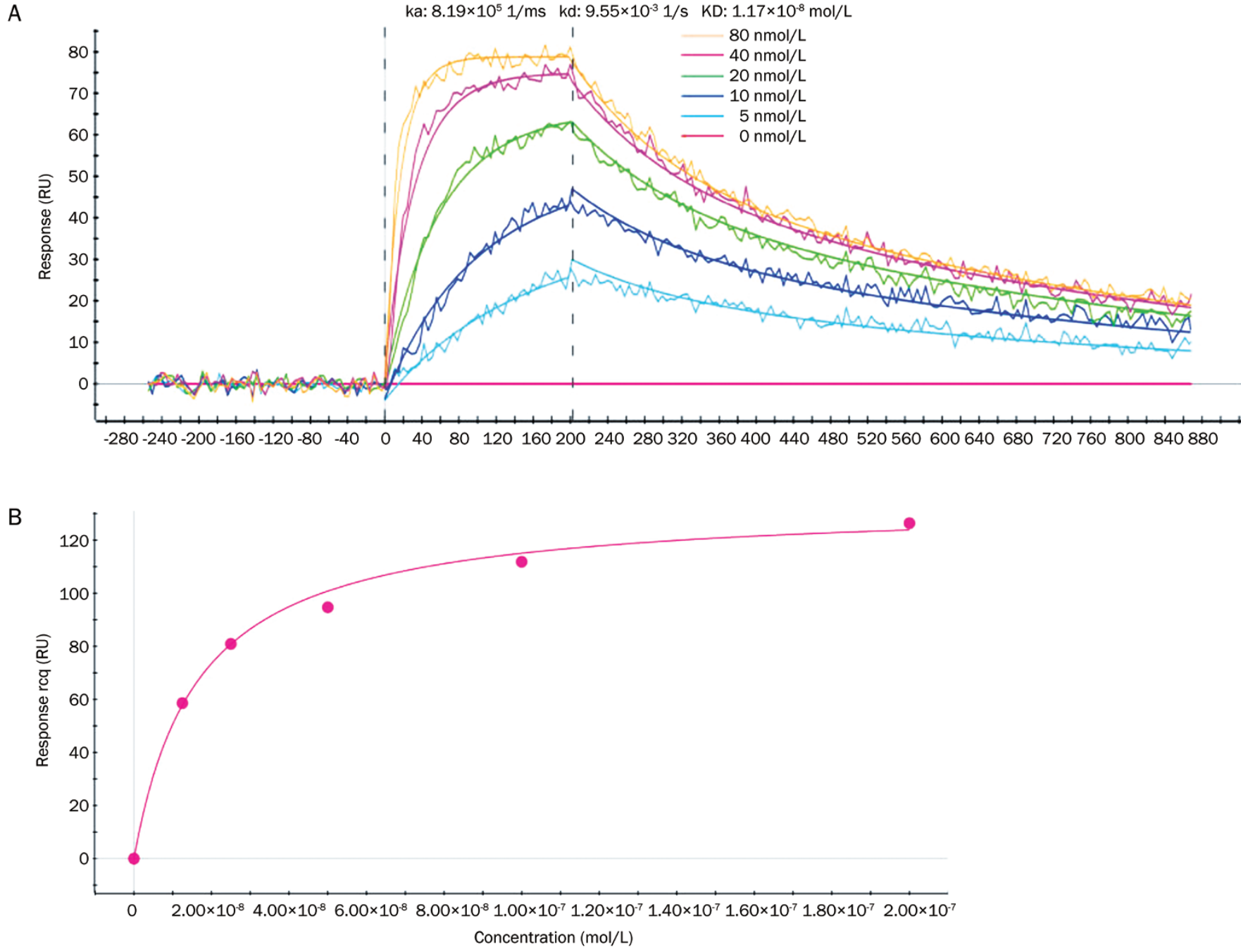

Figure 4. JG6 binds to CXCL12. (A) Binding response curve. (B) Equilibrium dissociation curve. Surface plasmon resonance (SPR) analysis of the interaction between JG6 and CXCL12. CXCL12 was injected at a concentration of 80,40, 20, 10, $5 \mathrm{nmol} / \mathrm{L}$ (from top to bottom). The equilibrium dissociation constant was calculated by BIAcore software 3.1. 
A

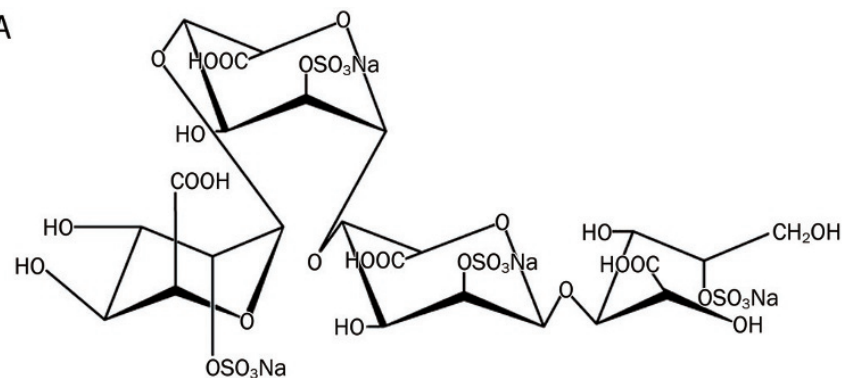

B

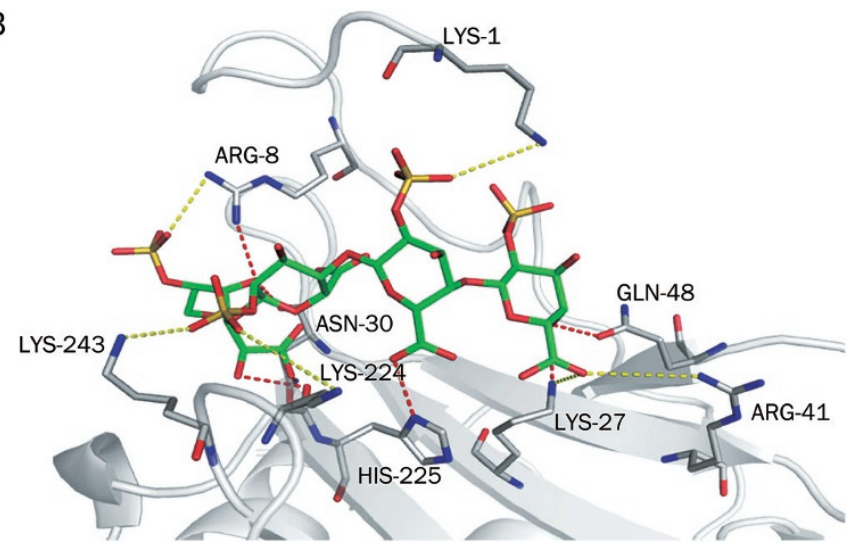

Figure 5. The interaction mode of JG6 and CXCL12 modeled by molecular docking. (A) The structure of JG6 in disaccharide form. (B) The interaction mode of JG6 and CXCL12. CXCL12 is shown in the white cartoon with JG6 shown as green sticks. The key residues from CXCL12 that interact with JG6 are also shown as sticks. Hydrogen bonds are indicated by red dashed lines, and ion bonds are indicated by yellow dashed lines.

HS, directly binds to CXCL12 in a multivalent binding mode, which was consistent with the molecular docking model of the interaction. The calculated energy showed that JG6 can effectively bind to CXCL12 with a relatively low energy (-13.28 $\mathrm{kcal} / \mathrm{mol})$. Together, these results suggest that JG6 may directly interact with CXCL12, thereby blocking the CXCL12/ CXCR4 axis and the subsequent biological functions such as tumor growth and migration.

In summary, our study shows that the structural features of JG6 enable it to interact with CXCL12 and provides an alternative for targeting the CXCL12/CXCR4 axis. The impact of JG6 on the CXCL12/CXCR4 axis may account for the anticancer activity of JG6.

\section{Acknowledgements}

The project was supported by the National Natural Science Foundation of China (№ 81072666) and the National Basic Research Program Grant of China (№ 2013CB932503).

\section{Author contribution}

Wei-wei WEN, Yi CHEN, and Jian DING designed the study; Wei-wei WEN performed experiments, analyzed the results and wrote the manuscript; Yi CHEN, Jian DING, and Meiyu GENG revised the manuscript; Xian-ling XIN synthesized compounds; and Shao XIE was involved in part of the study.

\section{References}

1 Sun X, Cheng G, Hao M, Zheng J, Zhou X, Zhang J, et al. CXCL12/ CXCR4/CXCR7 chemokine axis and cancer progression. Cancer Metastasis Rev 2010; 29: 709-22.

2 Balkwill F. Cancer and the chemokine network. Nat Rev Cancer 2004; 4: 540-50.

3 Du R, Lu KV, Petritsch C, Liu P, Ganss R, Passegue E, et al. HIF1alpha induces the recruitment of bone marrow-derived vascular modulatory cells to regulate tumor angiogenesis and invasion. Cancer Cell 2008; 13: 206-20.

4 Kojima Y, Acar A, Eaton EN, Mellody KT, Scheel C, Ben-Porath I, et al. Autocrine TGF-beta and stromal cell-derived factor-1 (SDF-1) signaling drives the evolution of tumor-promoting mammary stromal myofibroblasts. Proc Natl Acad Sci U S A 2010; 107: 20009-14.

5 Liekens S, Schols D, Hatse S. CXCL12-CXCR4 axis in angiogenesis, metastasis and stem cell mobilization. Curr Pharm Des 2010; 16: 3903-20.

6 Patrussi L, Baldari CT. The CXCL12/CXCR4 axis as a therapeutic target in cancer and HIV-1 infection. Curr Med Chem 2011; 18: 497 512.

7 Brule S, Friand V, Sutton A, Baleux F, Gattegno L, Charnaux N. Glycosaminoglycans and syndecan-4 are involved in SDF-1/CXCL12mediated invasion of human epitheloid carcinoma HeLa cells. Biochim Biophys Acta 2009; 1790: 1643-50.

8 Laguri C, Arenzana-Seisdedos F, Lortat-Jacob H. Relationships between glycosaminoglycan and receptor binding sites in chemokinesthe CXCL12 example. Carbohydr Res 2008; 343: 2018-23.

9 Lortat-Jacob $\mathrm{H}$. The molecular basis and functional implications of chemokine interactions with heparan sulphate. Curr Opin Struct Biol 2009; 19: 543-8.

10 Sutton A, Friand V, Brule-Donneger S, Chaigneau T, Ziol M, SainteCatherine 0 , et al. Stromal cell-derived factor-1/chemokine (C-X-C motif) ligand 12 stimulates human hepatoma cell growth, migration, and invasion. Mol Cancer Res 2007; 5: 21-33.

11 Friand V, Haddad O, Papy-Garcia D, Hlawaty H, Vassy R, HammaKourbali $Y$, et al. Glycosaminoglycan mimetics inhibit SDF-1/ CXCL12-mediated migration and invasion of human hepatoma cells. Glycobiology 2009; 19: 1511-24.

12 Zhang J, Chen Y, Xin XL, Li QN, Li M, Lin LP, et al. Oligomannurarate sulfate blocks tumor growth by inhibiting NF-kappaB activation. Acta Pharmacol Sin 2010; 31: 375-81.

13 Li QN, Liu HY, Xin XL, Pan QM, Wang L, Zhang J, et al. Marine-derived oligosaccharide sulfate (JG3) suppresses heparanase-driven cell adhesion events in heparanase over-expressing $\mathrm{CHO}-\mathrm{K} 1$ cells. Acta Pharmacol Sin 2009; 30: 1033-8.

14 Friesner RA, Banks JL, Murphy RB, Halgren TA, Klicic JJ, Mainz DT, et al. Glide: a new approach for rapid, accurate docking and scoring. 1. Method and assessment of docking accuracy. J Med Chem 2004; 47: 1739-49.

15 Friesner RA, Murphy RB, Repasky MP, Frye LL, Greenwood JR, Halgren $\mathrm{TA}$, et al. Extra precision glide: docking and scoring incorporating a model of hydrophobic enclosure for protein-ligand complexes. J Med Chem 2006; 49: 6177-96.

16 Sadir R, Imberty A, Baleux F, Lortat-Jacob H. Heparan sulfate/heparin oligosaccharides protect stromal cell-derived factor-1 (SDF-1)/CXCL12 against proteolysis induced by CD26/dipeptidyl peptidase IV. J Biol Chem 2004; 279: 43854-60.

17 Salmivirta M, Lidholt K, Lindahl U. Heparan sulfate: a piece of information. FASEB J 1996; 10: 1270-9.

18 Murphy KJ, Merry CL, Lyon M, Thompson JE, Roberts IS, Gallagher JT. A new model for the domain structure of heparan sulfate based on the novel specificity of K5 lyase. J Biol Chem 2004; 279: 27239-45.

19 Rueda P, Balabanian K, Lagane B, Staropoli I, Chow K, Levoye A, et al. The CXCL12gamma chemokine displays unprecedented structural and functional properties that make it a paradigm of chemoattractant proteins. PLoS One 2008; 3: e2543. 